\title{
Antitumour Activity of Purified Arabinogalactan-peptidoglycan Complex of the Cell Wall Skeleton of Rhodococcus lentifragmentus
}

\author{
By OSAMU HIRAI, * TAKASHI FUJITSU, JOH MORI, \\ HIROYUKI KIKUCHI, SHIGETAKA KODA, MAMORU FUJIOKA \\ AND YUKIYOSHI MORIMOTO \\ Research Laboratories, Fujisawa Pharmaceutical Co. Ltd, 2-1-6 Kashima, Yodogawa-ku, \\ Osaka 532, Japan
}

(Received 3 June 1986; revised 17 September 1986)

\begin{abstract}
Antitumour activity of arabinogalactan-peptidoglycan (AP) complex (peptidoglycan and arabinogalactan liberated by an acid or alkaline treatment from Rhodococcus lentifragmentus AN-115 cell wall skeleton) was examined in mice and compared with that of the cell wall skeleton. The growth of syngeneic fibrosarcoma Meth A cells after implantation in BALB/c mice was significantly suppressed by AP complex, and also regressed after intratumoral injection of AP complex on days 1, 4 and 7 after tumour implantation. Although the activity of peptidoglycan was less than that of AP complex, peptidoglycan also showed both tumoursuppressive and regressive activities. Arabinogalactan did not show antitumour activity. It is interesting that peptidoglycan has an important role in the effect against tumours.
\end{abstract}

\section{INTRODUCTION}

The cell wall skeleton of Rhodococcus lentifragmentus (R-CWS) possesses immunoadjuvant activity for circulating antibody formation (Ohara et al., 1986), and results in induction of cellmediated immunity and antitumour activity in experimental animals (Azuma et al., 1976; Yamawaki et al., 1978). Cell wall skeletons of various bacteria, such as Mycobacterium bovis BCG, Nocardia asteroides 131 and Corynebacterium diphtheriae PW8, also have adjuvant activity (Azuma et al., 1975). These bacteria have similar cell wall constituents: mycolic acid, arabinogalactan and peptidoglycan (Lederer, 1971; Michel \& Bordet, 1976; Barksdale \& Kim, 1977). Among these constituents, peptidoglycan is responsible for adjuvant activities of cell walls, causing increased serum antibody levels and inducing delayed-type hypersensitivity to ovalbumin (Azuma et al., 1975). Detailed studies on adjuvant-active units using enzymedegraded components of cell walls (Azuma et al., 1974; Adam et al., 1976) and synthesized model compounds (Adam et al., 1974) have shown that the $N$-acetylmuramyl-L-alanyl-Disoglutamine (MDP) fragment of peptidoglycan is the minimum unit needed to display the adjuvant activities. However, antitumour activity has not been demonstrated for MDP in experimental tumour systems. Furthermore, little is known about the antitumour activity of peptidoglycan moieties purified from bacterial cell walls, nor is it known how other constituents, especially arabinogalactan, relate to the antitumour activity of peptidoglycan. This paper describes antitumour activity of R-CWS and its constituents including the arabinogalactanpeptidoglycan complex (AP complex), peptidoglycan and arabinogalactan isolated from RCWS.

\section{METHODS}

$R-C W S$. This was prepared from 'Nocardia rubra' No-115 preserved in the Research Laboratories of Fujisawa Pharmaceutical Co. Organisms labelled ' $N$. rubra' should properly be considered as members of the species

Abbreviations: AP, arabinogalactan-peptidoglycan; MDP, $N$-acetylmuramyl-L-alanyl-D-isoglutamine; R-CWS, cell wall skeleton of $R$. lentifragmentus. 
Rhodococcus lentifragmentus (Tsukamura, 1985). Culture conditions and preparation of cell walls have been described by Fujioka et al. (1985).

Mycolic acid. Mycolic acids of R-CWS were obtained according to Koda et al. (1986).

AP complex. R-CWS was hydrolysed with $0.5 \%(\mathrm{w} / \mathrm{v}) \mathrm{KOH} / \mathrm{methanol}$ solution at $37^{\circ} \mathrm{C}$ for $48 \mathrm{~h}$ under nitrogen. After neutralization with concentrated $\mathrm{HCl}$, the mixture was evaporated to a syrup and then suspended in water. The suspension was washed with diethyl ether, filtered and washed with water, ethanol/diethyl ether $(1: 1, \mathrm{v} / \mathrm{v})$, chloroform and chloroform/methanol/water $(10: 10: 1$, by vol.). The residue was resuspended in water and lyophilized to yield the AP complex.

Arabinogalactan. The AP complex was hydrolysed with $1 \mathrm{M}-\mathrm{NaOH}$ at $70^{\circ} \mathrm{C}$ for $24 \mathrm{~h}$ under nitrogen. After neutralization with acetic acid, the mixture was concentrated by evaporation and successively filtered (pore sizes $3.0,0.8$ and $0.45 \mu \mathrm{m}$ ). The filtrate was dialysed against water for $4 \mathrm{~d}$, and concentrated by evaporation. This solution was applied to a column of Dowex $50 \mathrm{~W} \mathrm{X} 8\left(\mathrm{H}^{+}\right.$form) and eluted with water. The eluate was evaporated to a smaller volume and applied to a column of DEAE-cellulose DE52 ( $\mathrm{OH}^{-}$form). The arabinogalactan was eluted with water and lyophilized.

Peptidoglycan. The AP complex was hydrolysed with $0 \cdot 1 \mathrm{M}-\mathrm{HCl}$ at $60^{\circ} \mathrm{C}$ for $12 \mathrm{~h}$. The mixture was filtered and washed with water to remove $\mathrm{HCl}$. The residue was suspended in water and then lyophilized to yield the peptidoglycan.

Analytical methods for each fraction have been described by Fujioka et al. (1985).

Animals and tumours. BALB/c mice (8-12 weeks old) purchased from Shizuoka Jikken-Dobutsu Norkyo (Shizuoka), were given feed (from Oriental Yeast Industries Ltd, Osaka) and water ad lib. Mouse fibrosarcoma Meth A cells, which were chemically induced in BALB/c mice with methylcholanthrene, were serially passed in ascites form in syngeneic BALB/c mice.

Tumour suppression test. A single-cell suspension of Meth A fibrosarcoma in Hanks' balanced salt solution was mixed with R-CWS, or each constituent purified from R-CWS, suspended in saline containing a placebo preparation (a lyophilized preparation including squalene, polysorbate 80 and $D-$ mannitol, $4: 1: 28 \cdot 2$ by wt, mixed thoroughly with the sample and suspended in saline just before use). The mixture of tumour cell suspension and the sample suspension was injected intradermally into syngeneic BALB/c mice and the tumour sizes at the inoculated sites were measured every week.

Tumour regression test. BALB/c mice were injected intradermally with $1 \times 10^{5}$ Meth A cells, and on days 1,4 and 7 after tumour cell inoculation, R-CWS, or each constituent purified from R-CWS, mixed with the placebo preparation in saline was injected intralesionally. Tumours were dissected out and weighed on day 14.

Statistical analysis. Tumour size and weight were subjected to the Student's $t$-test and Cochran-Cox test, and inhibition rates of tumour take were subjected to Fisher's exact probability test.

\section{RESULTS}

Chemical composition of R-CWS and constituents purified from it. R-CWS was mainly composed of mycolic acid, arabinogalactan and peptidoglycan. The latter two constituents were bound together by phosphodiester linkages and glycosidic linkages to form the rigid structure of the AP complex (Fujioka et al., 1985). Mycolic acid was bound to the arabinogalactan moiety of this complex through ester bonds. As shown in Table 1, the arabinogalactan consisted of arabinose and galactose together with small amounts of rhamnose. The peptidoglycan consisted of glucosamine, muramic acid, alanine, glutamic acid and diaminopimelic acid.

Antitumour activities of $R-C W S$ and constituents purified from it. AP complex and R-CWS at doses of 10 and $100 \mu \mathrm{g}$ suppressed the growth of fibrosarcoma Meth A in BALB/c mice (Table 2). Peptidoglycan also showed tumour-suppressive activity at a dose of $100 \mu \mathrm{g}$, but not at a dose of $10 \mu \mathrm{g}$. Arabinogalactan did not suppress tumour growth even at a dose of $100 \mu \mathrm{g}$.

Regression of the growth of Meth A was evident in BALB/c mice that received doses of 100 and $320 \mu \mathrm{g}$ of AP complex (Table 3). Peptidoglycan also showed significant tumour-regressive activity at a dose of $320 \mu \mathrm{g}$ (Table 4). No tumour-regressive activity was observed in the case of arabinogalactan; its effect was similar to that seen in the suppression test (data not shown).

\section{DISCUSSION}

Intratumoral administration of the cell wall skeletons of Mycobacterium bovis BCG and of Corynebacterium parvum can protect experimental animals from proliferation of tumours (Azuma et al., 1974). In the present study, R-CWS also showed strong suppressive and regressive 
Table 1. Chemical composition (percentage by weight) of R-CWS and constituents purified from it

For R-CWS the mean values of five different preparations are given. Other values were obtained by a single determination.

\begin{tabular}{|c|c|c|c|c|}
\hline Component & R-CWS & AP complex & Peptidoglycan & Arabinogalactan \\
\hline Lipids & $27.6 \pm 0.7$ & $1 \cdot 2$ & 0.9 & ND \\
\hline \multicolumn{5}{|l|}{ Sugars } \\
\hline Arabinose & $15.2 \pm 0.4$ & $27 \cdot 9$ & - & $67 \cdot 9$ \\
\hline Galactose & $8.9 \pm 0.3$ & $15 \cdot 1$ & - & $32 \cdot 0$ \\
\hline Rhamnose & $0.92 \pm 0.04$ & $1 \cdot 3$ & - & $2 \cdot 4$ \\
\hline \multicolumn{5}{|l|}{ Amino sugars } \\
\hline Glucosamine & $4.8 \pm 0 \cdot 2$ & $8 \cdot 0$ & $12 \cdot 7$ & $0 \cdot 6$ \\
\hline Muramic acid & $6.2 \pm 0.3$ & $11 \cdot 3$ & $16 \cdot 8$ & $0 \cdot 08$ \\
\hline \multicolumn{5}{|l|}{ Amino acids } \\
\hline Alanine & $8.5 \pm 0.3$ & $8 \cdot 6$ & $15 \cdot 1$ & $0 \cdot 03$ \\
\hline Glutamic acid & $5.8 \pm 0.2$ & $7 \cdot 3$ & $13 \cdot 3$ & $0 \cdot 03$ \\
\hline Diaminopimelic acid & $7.2 \pm 0.2$ & $10 \cdot 4$ & $19 \cdot 2$ & $0 \cdot 15$ \\
\hline Glycine & $1.2 \pm 0.1$ & $0 \cdot 2$ & 0.4 & - \\
\hline Serine & $1.7 \pm 0.1$ & $0 \cdot 1$ & $0 \cdot 1$ & - \\
\hline Threonine & $1.4 \pm 0.2$ & $0 \cdot 1$ & $0 \cdot 1$ & - \\
\hline Leucine & $1.2 \pm 0.1$ & $0 \cdot 2$ & $0 \cdot 3$ & - \\
\hline Phenylalanine & $1.5 \pm 0.2$ & $0 \cdot 3$ & - & - \\
\hline Phosphorus & $0.09 \pm 0.01$ & $0 \cdot 1$ & ND & ND \\
\hline Loss on drying & $7.2 \pm 1.5$ & $11 \cdot 9$ & ND & ND \\
\hline
\end{tabular}

Table 2. Suppressive effects of $R$-CWS and constituents purified from it on fibrosarcoma Meth $A$ in $B A L B / c$ mice Mice were inoculated intradermally with a mixture of syngeneic Meth A cells $\left(1 \times 10^{5}\right)$ and R-CWS or
a constituent purified from R-CWS. The results were obtained on day 21 after the tumour cell
implantation, when the mean tumour size in placebo and saline control groups was, respectively, $16 \cdot 1 \pm$
1.43 and $16 \cdot 1 \pm 2 \cdot 10$ (expt I), and $15 \cdot 1 \pm 2.81$ and $15 \cdot 5 \pm 2.28 \mathrm{~mm}$ (expt II).

\begin{tabular}{|c|c|c|c|}
\hline \multirow[b]{2}{*}{ Sample } & \multirow{2}{*}{$\begin{array}{c}\text { Dose } \\
(\mu \mathrm{g} \text { per } 0.05 \mathrm{ml} \\
\text { per mouse })\end{array}$} & \multicolumn{2}{|c|}{$\begin{array}{l}\text { No. of mice with tumour } \\
\text { no. of mice used }\end{array}$} \\
\hline & & Expt I & Expt II \\
\hline \multirow[t]{2}{*}{$\mathrm{R}-\mathrm{CWS}$} & 10 & NT & $1 / 10^{* *}$ \\
\hline & 100 & $0 / 10^{* *}$ & $0 / 10^{* *}$ \\
\hline \multirow[t]{3}{*}{ AP complex } & 10 & NT & $3 / 10^{* *}$ \\
\hline & 32 & NT & $2 / 10^{* *}$ \\
\hline & 100 & $0 / 10^{* *}$ & $0 / 10^{* *}$ \\
\hline \multirow[t]{2}{*}{ Peptidoglycan } & 10 & NT & $8 / 10$ \\
\hline & 100 & $1 / 10^{* *}$ & $0 / 10^{* *}$ \\
\hline Arabinogalactan & 100 & $10 / 10$ & $8 / 10$ \\
\hline Placebo control & 0 & $10 / 10$ & $10 / 10$ \\
\hline Saline control & 0 & $10 / 10$ & $10 / 10$ \\
\hline
\end{tabular}

effects on syngeneic fibrosarcoma Meth $\mathrm{A}$ in BALB/c mice. Furthermore, significant antitumour activity of the AP complex and peptidoglycan against the Meth A growth was observed.

The minimal adjuvant-active subunit of BCG cell walls is MDP (Elouz et al., 1974; Kotani et al., 1975; Azuma et al., 1983). Synthetic $N$-acetylmuramyl-dipeptide that had potent adjuvant activity in immune systems, however, proved to be active in experimental tumour systems only if administered admixed with trehalose dimycolate (McLaughlin et al., 1980; Yarconi et al., 1981), or incorporated into liposomes (Fidler et al., 1981). Saiki et al. (1982) speculated that the 
Table 3. Regressive effect of $A P$ complex on growth of syngeneic fibrosarcoma Meth $A$ in $B A L B / c$ mice

Meth A cells $\left(1 \times 10^{5}\right)$ were implanted intradermally on day 0 and a sample was injected intratumorally on days 1,4 and 7 . Ten animals were used in each dose and control group. Tumours were dissected out and weighed on day 14 . The numbers in parentheses show the tumour growth inhibition rate: $(1-T / C)$ $\times 100(\%)$, where $T$ is the tumour weight of the sample-treated group and $C$ is the tumour weight of the placebo-treated control group.

\begin{tabular}{|c|c|c|c|c|}
\hline \multirow{2}{*}{$\begin{array}{l}\text { Sample } \\
\text { AP complex }\end{array}$} & \multirow{2}{*}{$\begin{array}{c}\text { Dose } \\
\left(\mu \mathrm{g} \text { per mouse } \mathrm{d}^{-1}\right) \\
320\end{array}$} & \multicolumn{3}{|c|}{ Mean tumour wt $(\mathrm{mg})$ on day $14, \pm \mathrm{SE}$} \\
\hline & & Expt I & Expt II & Expt III \\
\hline AP complex & $\begin{array}{r}320 \\
100 \\
32 \\
10\end{array}$ & $\begin{array}{c}\mathrm{NT} \\
211 \pm 54^{*} \dagger(55) \\
389 \pm 41 \dagger \quad(18) \\
473 \pm 49 \dagger \quad(0)\end{array}$ & $\begin{array}{rr}32 & \pm 8^{*} \\
207 & \pm 49 \dagger \\
243 & \pm 46 \\
377 & \pm 33\end{array}$ & $\begin{array}{c}144 \pm 44^{* \dagger}(73) \\
280 \pm 62^{* \dagger}(48) \\
\text { NT } \\
N T\end{array}$ \\
\hline R-CWS & $\begin{array}{r}320 \\
100 \\
32 \\
10\end{array}$ & $\begin{array}{r}\text { NT } \\
34 \pm 8^{*}(93) \\
93 \pm 22^{*}(80) \\
201 \pm 29^{*}\end{array}$ & $\begin{array}{r}23 \pm 6^{*}(94) \\
58 \pm 24^{*}(85) \\
216 \pm 39 \\
329 \pm 32\end{array}$ & $\begin{array}{c}25 \pm 6^{*}(95) \\
57 \pm 16^{*}(89) \\
\text { NT } \\
\text { NT }\end{array}$ \\
\hline $\begin{array}{l}\text { Placebo control } \\
\text { Saline control }\end{array}$ & $\begin{array}{l}0 \\
0\end{array}$ & $\begin{array}{l}473 \pm 51 \\
504 \pm 49\end{array}$ & $\begin{array}{l}375 \pm 68 \\
387 \pm 43\end{array}$ & $\begin{array}{l}534 \pm 44 \\
408 \pm 55\end{array}$ \\
\hline
\end{tabular}

NT, Not tested.

* Significantly different from placebo-treated control group $(P<0.05)$

$\dagger$ Significantly different from the same dose group of R-CWS $(P<0.05)$.

Table 4. Effect of peptidoglycan on growth of syngeneic fibrosarcoma Meth $A$ in $B A L B / c$ mice

Meth A cells $\left(1 \times 10^{5}\right)$ were implanted intradermally on day 0 , and a sample was injected intratumorally on days 1,4 and 7 . Ten animals were used in each dose and control group. The tumour growth inhibition rate $(\%)$ is shown in parentheses. For other information, see Table 3.

\begin{tabular}{|c|c|c|c|}
\hline \multirow{3}{*}{$\begin{array}{c}\text { Sample } \\
\text { Peptidoglycan }\end{array}$} & \multirow{3}{*}{$\begin{array}{c}\text { Dose } \\
\left(\mu \mathrm{g} \text { per mouse } \mathrm{d}^{-1}\right) \\
320 \\
100 \\
32\end{array}$} & \multicolumn{2}{|c|}{ Mean tumour wt (mg) on day $14, \pm$ SE } \\
\hline & & Expt I & Expt Iİ \\
\hline & & $\begin{array}{lr}240 \pm 51^{* \dagger} & (46) \\
439 \pm 36 \dagger & (1) \\
492 \pm 32 \dagger \quad(-11)\end{array}$ & $\begin{array}{lr}229 \pm 39^{*} \dagger & (35) \\
338 \pm 46 \dagger & (5) \\
401 \pm 52 \dagger & (-13)\end{array}$ \\
\hline R-CWS & $\begin{array}{r}320 \\
100 \\
32\end{array}$ & $\begin{array}{r}19 \pm 5^{*} \\
46 \pm 15^{*} \\
226 \pm 58^{*}\end{array}$ & $\begin{array}{r}21 \pm 6^{*} \\
48 \pm 12^{*} \\
131 \pm 46^{*}\end{array}$ \\
\hline $\begin{array}{l}\text { Placebo control } \\
\text { Saline control }\end{array}$ & $\begin{array}{l}0 \\
0\end{array}$ & $\begin{array}{l}442 \pm 50 \\
353 \pm 38\end{array}$ & $\begin{array}{l}355 \pm 37 \\
341 \pm 60\end{array}$ \\
\hline
\end{tabular}

lack of antitumour activity of MDP might be due to its low molecular weight and water solubility. $\mathrm{N}$-Acetylmuramyl-dipeptide with mycolic acid bound to the 6-O-position of its muramic acid residue showed suppressive activity against experimental murine tumour growth in syngeneic mice (Kusumoto et al., 1978). Hrsak et al. (1983) reported that intratumorally administered peptidoglycan monomer, isolated from Brevibacterium divaricatum cell wall, inhibited the nodule growth of B-16 melanoma at a relatively high dose (1 mg per site). Peptidoglycan from acid-treated R-CWS contained a minute fraction of lipid (see Table 1). Since it seems unlikely that the lipid component is responsible for the antitumour activity of the peptidoglycan fraction, peptidoglycan is considered to be essentially the antitumour-active moiety and needs its polymer structure to display strong antitumour activity.

Saiki et al. (1982) and Kamisango et al. (1982) reported that peptidoglycan was obtained by mild acid treatment from the cell wall skeleton of Listeria monocytogenes without influencing its chemical nature or decreasing its adjuvant and antitumour activities. In the present experiments, however, the antitumour activity of peptidoglycan purified from R-CWS was less than that of the AP complex and R-CWS. Azuma et al. (1975) have shown that adjuvant 
activities of cell wall skeletons of $M$. bovis BCG and $N$. asteroides after acid treatment (peptidoglycan) significantly decreased because of the drastic acid treatment $\left(0 \cdot 1 \mathrm{M}-\mathrm{HCl}, 60^{\circ} \mathrm{C}\right.$, $24 \mathrm{~h})$.

Arabinogalactan itself showed no significant antitumour activity. However, the present results suggest that arabinogalactan enhances the antitumour activity of peptidoglycan, as judged by the difference in activities between peptidoglycan and the AP complex.

\section{REFERENCES}

Adam, A., Ciorbaru, R., Ellouz, F., Petit, J.-F. \& LEDERER, E. (1974). Adjuvant activity of monomeric bacterial cell wall peptidoglycans. Biochemical and Biophysical Research Communications 56, 561-567.

Adam, A., DeVys, M., Souvannavong, V., Lefrancier, P., ChoAy, J. \& LeDERER, E. (1976). Correlation of structure and adjuvant activity of $\mathrm{N}$ acetylmuramyl-L-alanyl-D-isoglutamine (MDP), its derivatives and analogues. Anti-adjuvant and competition properties of stereoisomers. Biochemical and Biophysical Research Communications 72, 339-346.

azuma, I., Taniyama, T., Hirao, F. \& Yamamura, Y. (1974). Antitumour activity of cell-wall skeletons and peptidoglycolipids of mycobacteria and related microorganisms in mice and rabbits. Gann 65, 493505.

azuma, I., Kanetsuna, F., Taniyama, T., HoRi, M. \& TANAKA, Y. (1975). Adjuvant activity of mycobacterial fractions. I. Purification and in vivo adjuvant activity of cell wall skeletons of Mycobacterium bovis BCG, Nocardia asteroides 131 and Corynebacterium diphtheriae PW8. Biken Journal 18, 1-13.

Azuma, I., TaniYama, T., Yamawaki, M., Sugimura, K. \& YamamuRA, Y. (1976). Adjuvant and antitumor activities of Nocardia cell-wall skeletons. Gann 67, 733-736.

azuma, I., Okumura, H., Saiki, I., Tanio, Y., Kiso, M., Hasegawa, A. \& Yamamura, Y. (1983). Adjuvant activity of carbohydrate analogs of $N$ acetylmuramyl-alanyl-D-isoglutamine on the induction of delayed-type hypersensitivity to azobenzenearsenate- $N$-acetyl-L-tyrosine in guinea pigs. Infection and Immunity 41, 462-469.

BARKSDALE, L. \& KIM, K. S. (1977). Mycobacterium. Bacteriological Reviews 41, 217-372.

Elouz, F., Adam, A., Ciorbaru, R. \& Lederer, E. (1974). Minimal structural requirements for adjuvant activity of bacterial peptidoglycan derivatives. Biochemical and Biophysical Research Communications 59, 1317-1325.

Fidler, I. J., Sone, S., Fogler, W. E. \& Barnes, Z. L. (1981). Eradication of spontaneous metastases and activation of alveolar macrophages by intravenous injection of liposomes containing muramyl dipeptide. Proceedings of the National Academy of Sciences of the United States of America 78, 1680-1684.

FujioKa, M., KodA, S. \& Morimoto, Y. (1985). Novel glycosidic linkage between arabinogalactan and peptidoglycan in the cell wall skeleton of Nocardia rubra AN-115. Journal of General Microbiology 131, 1325-1329.

HRSAK, I., Tomasic, J. \& OsmaK, M. (1983). Immunotherapy of B-16 melanoma with peptidoglycan monomer. European Journal of Cancer and Clinical Oncology 19, 681-686.

Kamisango, K., Saiki, I., Tanio, Y., Okumura, H.,
Araki, Y., Sekikawa, I., Azuma, I. \& Yamamura, Y. (1982). Structures and biological activities of peptidoglycans of Listeria monocytogenes and Propionibacterium acnes. Journal of Biochemistry 92, 2333.

Koda, S., Fujioka, M., Shigi, M., Nakashima, K. \& MoRIMOTO, Y. (1986). Structural analysis of mycolic acids from the cell wall skeleton of Rhodococcus lentifragmentus AN-115. Journal of General Microbiology 132, 1547-1551.

Kotani, S., Watanabe, Y., Kinoshita, F., Shimono, T., Morosaki, I., Shiba, T., Kusumoto, S., Tarumi, Y. \& IKENAKA, K. (1975). Immunoadjuvant activities of synthetic $N$-acetyl-muramyl-peptides or amino acids. Biken Journal 18, 105-111.

Kusumoto, S., Inage, M. \& Shiba, T. (1978). Synthesis of long chain fatty acid esters of $N$-acetylmuramyl$L$-alanyl-D-isoglutamine in relation to antitumor activity. Tetrahedron Letters 49, 4899-4902.

Lederer, E. (1971). The mycobacterial cell wall. Pure and Applied Chemistry 25, 135-165.

Mclaughlin, C. A., Schwartzman, S. M., Horner, B. L., Jones, G. H., MOfFatT, J. G., Nestor, J. J., JR \& TegG, D. (1980). Regression of tumors in guinea pigs after treatment with synthetic muramyl dipeptides and trehalose dimycolate. Science $\mathbf{2 0 8}$, 415-416.

Michel, G. \& BoRdeT, C. (1976). Cell wall of Nocardia. In The Biology of the Nocardiae, pp. 141159. Edited by M. Goodfellow, G. M. Brownell \& J. A. Serrano. London: Academic Press.

Ohara, K., Fujitsu, T., Sakuma, S., Ina, K., Senoh, H., MORI, J. \& KIKUCHI, H. (1986). Antigenicity of Nocardia rubra cell wall skeleton (N-CWS). (1) Antigenicity of N-CWS in mice and guinea pigs. Harmacometrics 31, 735-744.

Saiki, I., Kamisango, K., Tanio, Y., OKumura, H., YamamuRA, Y. \& AzUma, I. (1982). Adjuvant activity of purified peptidoglycan of Listeria monocytogenes in mice and guinea pigs. Infection and Immunity 38, 58-66.

TsukamuRa, M. (1985). Priority of Rhodococcus lentifragmentus (Kruse 1869; Tsukamura et al. 1975) Tsukamura 1978 comb. nov. over Rhodococcus ruber (Kruse 1896) Goodfellow and Alderson 1980. International Journal of Systematic Bacteriology 35, 124125.

Yamawaki, M., Azuma, I., SaIki, I., UemiYa, M., AOKI, O., EnNU, K. \& Yamamura, Y. (1978). Antitumor activity of squalene-treated cell wall skeleton of Nocardia rubra in mice. Gann 69, 619 626.

YARCoNI, E., Lederer, E. \& RAPP, H. J. (1981). Immunotherapy of experimental cancer with a mixture of synthetic muramyl dipeptide and trehalose dimycolate. Infection and Immunity 32, 273-276. 